to say that the work of the domestic science teachers in nutrition education has played a vital part in this happy state of affairs.

\title{
SUMMARY
}

The training colleges of domestic science offer a varied 3-year course; some have a definite bias towards one or other branch of this wide subject, but all build their work round the home and the needs of the various members of the household. Since good nutrition is a fundamental essential of family well-being, the study of nutrition education is common to all colleges. The previous preparation of students on entry to college varies considerably, but the nutrition course during their training follows four lines all leading to the practice of good nutritional habits based on scientific knowledge and to the ability to teach this to others. Though the student-in-training has ample help with her nutrition education, further stimulus and guidance are needed for the practising teachers, who all too often find it difficult to keep their nutrition knowledge up to date.

\section{The Education of Medical Students in Nutrition}

\author{
By S. J. Cowell, University College Hospital Medical School, \\ London, W.C.I
}

\section{The dual aspect of nutrition}

If and when we have agreed on an answer to the question 'What do practising doctors need to know about nutrition ?', we may be in a position to discuss the ways and means of giving medical students the knowledge they should be encouraged to acquire.

There are two distinct aspects of nutrition of importance to the medical practitioner. There is first the knowledge of general principles, which on the one hand will enable him to secure for the individuals and families in his care the perfection of development in early years that depends on right feeding and on the other hand will furnish him with a potent means of maintaining his older 'patients' in vigorous health. Secondly, the medical man requires a knowledge of how normal diets can be modified so that they may make their fullest contribution to the treatment of his individual patients when they fall sick.

I propose to give my views on the kind of knowledge of nutrition a medical man should possess and then to consider ways and means of giving it to the medical student. May I refer for a moment to the foundation in the University of London, in 1927 , of the Chair of Dietetics of which I am the original holder. This Chair was endowed through the initiative of a wealthy mother whose own doctor was unwilling or unable to offer her any advice, based on up-to-date nutritional science, on how to feed her young growing family. From inquiries she made it appeared that few, if any, clinical students at that time were being encouraged to take a real 
interest in nutritional science, in spite of the fact that for 20 years biochemists, physiologists, pharmacologists and physicians had been turning out abundant evidence of the importance of the chemical make-up of the diet for securing perfect development of the young growing animal and the maintenance alike of young and old in a state of robust health, protected from a variety of deficiency states that could result from an imperfect or incomplete diet. She believed that the creation of a University Chair might draw attention of teachers in Medical Schools to the importance of nutritional science in the training of young doctors, and largely as the result of her efforts, financial and otherwise, funds were collected to endow such a Chair in the University of London.

The title of this Chair, be it noted, was the Chair of Dietetics, not the Chair of Nutrition. The distinction between the two terms was not so definite then as now, and it is clear that the foundation of the Chair was designed as much to encourage the doctors of the future to be in a position to advise their patients on how to use diet to make and keep themselves fit and well as to teach them how to modify 'normal' diets for the treatment of established disease.

Few would now dispute the proposition that the doctor should be competent to offer dietary advice to all under his care or influence. Diet has been considered an integral part of the doctor's therapeutic armamentarium for as long as records of medical activities are available, but at no time have there been more compelling reasons than now why doctors should make full use of available nutritional knowledge. This is not solely because the physician, even in a comparatively well-fed country like our own, has opportunities of diagnosing nutritional deficiencies amenable to appropriate treatment, if he has the necessary knowledge and experience; in addition, a thorough acquaintance with the 'newer knowledge of nutrition' will be of great value in his treatment of patients whose illnesses and disorders may have no obvious relation to faulty feeding. It is not only the general practitioner and the physician who benefit from a knowledge of nutrition. Such knowledge is proving of great practical value to the obstetrician in antenatal and postnatal clinics and to the paediatrician who, if he is handicapped by being a specialist, in contrast with the family doctor who is his own paediatrician and obstetrician, will need to work with the obstetrician's team to secure the best results of good feeding. Similarly, modern surgical methods involve the use of nutritional knowledge to assist in both the pre-operative and post-operative treatment of a great variety of patients. There is also the sphere of mental disorder, in which the determination by nutritional deficiencies of the onset of psychopathic states has been firmly established in recent years.

Those engaged in treating the sick should not only be acquainted with the nutritional needs of ordinary healthy people, but should also know how 'ordinary' diets can be modified for longer or shorter periods, to assist in treating a variety of diseases that traditional experience and clinical research have shown to be benefitted by dietary adjustments. The doctor must be sufficiently familiar with this branch of knowledge to be able to ensure that the basic nutritional needs of his patients are fully met, no matter what dietary modifications he advises. However 
'light' or 'soft' the diet is to be, whatever its content of fibre, protein, fat or carbohydrate and whether it is to be fattening or reducing, the prescriber must be satisfied that the ordered quantities of the specified foods do in fact contain essential nutrients sufficient to enable the body to carry on as vigorously as possible its normal metabolism. There is no excuse in this day and generation for any 'morbus e medico' to appear as the result of dietary mismanagement.

\section{The essential knowledge}

If we now agree that the efficient doctor should be in a position to advise all and sundry on how to choose for themselves health-promoting diets and to prescribe for his own patients suitable modifications of the ordinary good diet to assist in therapy, can we agree as to what he ought to know about food and nutritional processes, and how may he best acquire this knowledge?

It is not easy to find out just how much medical students are taught of nutrition and dietetics in our medical schools to-day. They have probably all been taught a good deal about the chemical composition of foods, the distribution of nutrients in common foods, the energy exchanges associated with life and muscular activity and the more important chemical processes associated with digestion and metabolism. This indispensable knowledge they acquire as part of their pre-clinical training in physiology and biochemistry.

It is, however, unlikely that they will appreciate to the full the significance of nutritional knowledge in relation to human health until they come in contact with children whose development has been delayed or stunted as a result of feeding errors, adults whose general health is impaired through unwise food habits and patients in whom symptoms of bodily disorders are seen to be amenable to dietary adjustments. This means to say that during their clinical training they will derive much benefit from being under the influence of teachers who are familiar with the more important chemical, physiological and clinical aspects of nutrition, are constantly on the look-out for indications of the part that dietary errors could have played in promoting disease and ill-health and are prepared to make full use of diet as a therapeutic aid.

Clinical teachers then should be available with an up-to-date knowledge of nutrition; they should be as familiar with the chemical composition of common foods as with the pharmacological make-up of common drugs; they must be capable of appraising claims by the purveyors of new special foods and preparations of vitamins as critically as they assess the advertised virtues of new drugs and medical appliances. Are these clinical teachers to be heads of special departments of nutrition with a footing in a medical school and possibly access to hospital patients, or are they to be the physicians and surgeons teaching medicine and surgery in the wards? The question reminds me of a similar one being asked just now about the teaching of social medicine to medical students. Some medical schools treat the social aspects of medicine, the relation of health and disease to environmental, genetic, economic and industrial factors, as a speciality to be 
taught by those wholly engaged in their study. There have sprung up, mainly outside London, Chairs and Departments of Social Medicine, which have undertaken the instruction of students in the 'social' aspects of health and ill-health. But there is another way of coping with such teaching, a way favoured by many medical schools in London, including the one with which I am associated. Isn't it better, it can be argued, for every clinical teacher to be so conscious of the importance of 'social' factors in determining the state of health, that he takes them into account and discusses them with his students as a matter of course in his day-to-day inquiries into the causes of ill-health and disease and in his hospital and follow-up treatment of sick people? Students will acquire more readily from such bed-side and out-patient teaching the habit of associating environmental factors with their day-to-day clinical problems than if they relied on courses of lectures and demonstrations from experts in social medicine.

This is not to say that 'experts' should have no say in the teaching of social aspects of medicine. There are many subjects that a Medical Officer of Health, an occupational physician or an epidemiologist could well be asked to put across to the medical student. In the same way there are certain aspects of nutrition and dietetics that could be taught by an expert, by means of lectures, and by demonstrations, which could well include the preparation of special diets by a qualified dietitian.

The young doctor beginning to pràctise outside his hospital may find that some of his patients have very definite ideas about diet, and he may find that he is expected to talk intelligently, and to offer authoritative opinions, about such varied subjects as, to quote a few of topical interest, the use of flour improvers, the iodization of salt and the fluoridation of water, vegetarianism, the effect of dietary factors on resistance to dental caries, the comparative value of natural and artificial fertilizers for the production of health-promoting foods. It may be argued that the qualified doctor can read up these subjects in his medical journals, and it is therefore not necessary to fill up the precious teaching hours of the medical student with such frills. I would submit, however, that it is possible for a student's attention to be so attracted during his years of training to some particular aspects of medicine, such as nutrition and dietetics, that he retains an interest in them for the rest of his days, and this may be a justification for a certain amount of special teaching from an 'expert'.

What other facilities for education in nutrition can be offered to medical students ? In some teaching hospitals there may be special clinics and research units dealing with nutritional problems. The student may gain much from attendance at obesity clinics, special metabolic units and antenatal clinics where instruction is given to mothers on how to feed themselves and their babies. These all have some contribution to make to the education of the student in nutrition, but it is the day-to-day presentation to the student by his regular clinical teachers of the feeding problems needing to be examined and solved as a routine for their general run of in- and out-patients that, I submit, will give the student the interest in, and respect for, nutritional knowledge able to stand him in good stead throughout his career as a practising doctor. 